\title{
Shamanism and Indian rock art
}

\section{Comment in response to David Lewis-Williams' paper 'Shamanism: a contested concept in archaeology' Before Farming 2006/4 article 1}

\section{Nicole Boivin}

Leverhulme Centre for Human Evolutionary Studies, The Henry Wellcome Building, University of Cambridge, Fitzwilliam Street, Cambridge CB2 1QH

n.boivin@human-evol.cam.ac.uk

In 1997, while conducting ethnoarchaeological field work in northwestern India, I witnessed the activities of a bhopa - a type of ritual specialist that my dictionary translated as shaman. The bhopa was a low caste man from another village who, after a short period of drumming, was possessed by the local deity Mata-ji, and proceeded to dispense cures for ailments, predict the future and address disputes. A number of years later, while writing about south Indian prehistoric rock art, I speculated in a throw-away comment that, given its association with rock gongs and apparently ritual sites, some of the art may have been produced by such “'shaman'-like individuals" (Boivin 2004: 48). I had no idea at the time what a potentially divisive interpretation this was, nor that it connotated a very particular kind of model in rock art studies. This shamanistic model seems to elicit vehement responses and debate amongst rock art specialists (Chippindale 2003). While I gather that some of this is highly personal, much of it likely also reflects the fact that the model is a productive one. If we judge interpretations and hypotheses according to Oscar Wilde's dictum that 'there is only

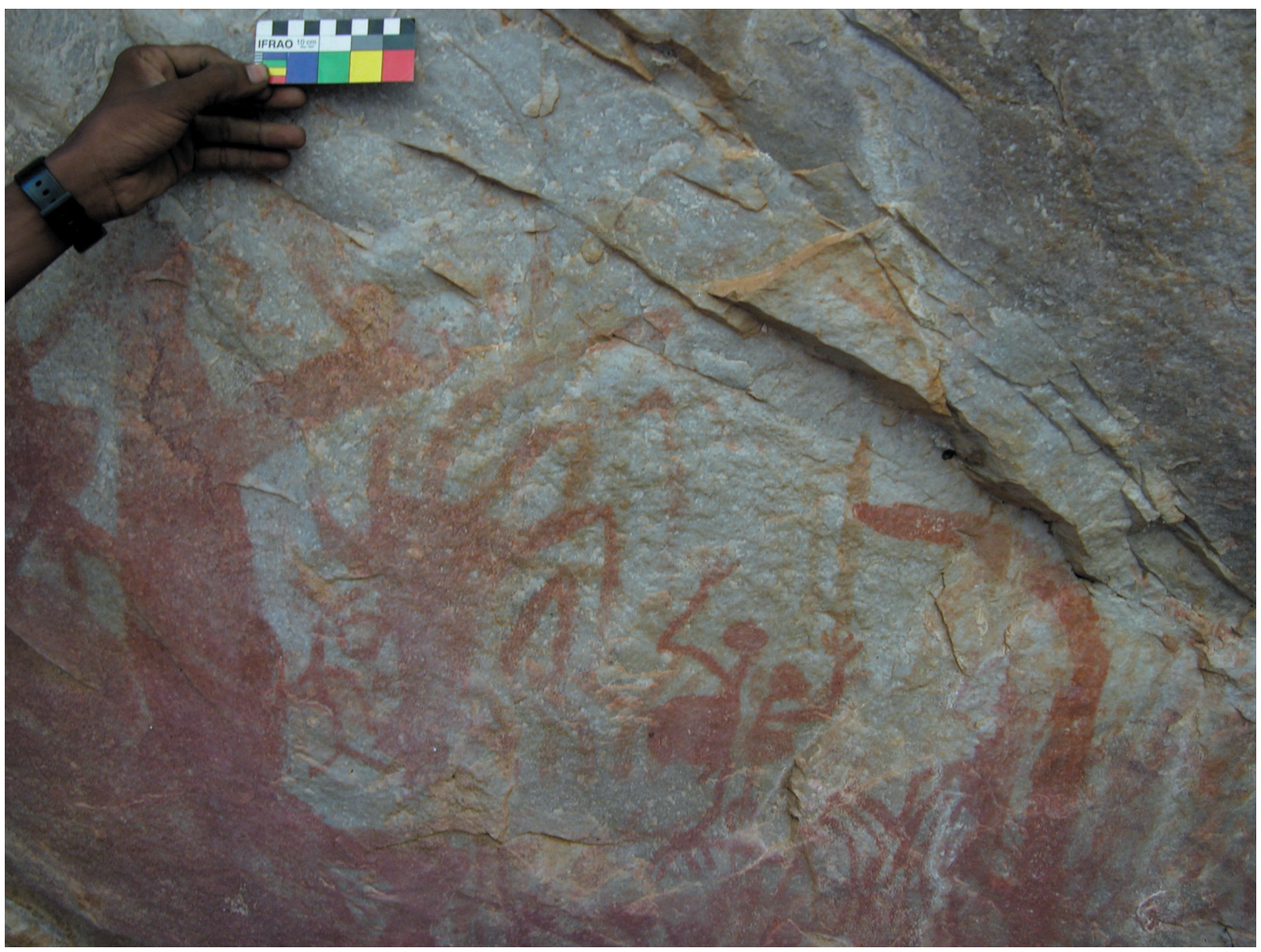

Figure 1 Rock art panel from Kurnool District, south India, depicting various extraordinary-looking, part human creatures 
one thing in the world worse than being talked about, and that is not being talked about', then the shamanistic model is doing just fine. Interpretations that are really bad, even if they elicit critique, are usually quickly ignored and fall by the wayside. Interpretations that get people very emotional and angry usually do so because they have also attracted positive attention; some feel this is unmerited, and this drives further research to test the hypothesis - all signs of a productive model.

The idea that all rock art is produced by shamans is of course silly, though when someone comes up with a good idea (like ancestors in the British Neolithic), it can be tempting to apply it widely. This is why LewisWilliams' argument concerning the need to construct a persuasive 'cable' from various strands of evidence is important. Alison Wylie's insights into archaeological epistemology remain as valid now as when they were published almost two decades ago. Thus we do not, for example, only examine rock art images, but also their place on the rock surface, their location in the wider landscape, and the archaeology (or lack thereof) associated with them. This is why the shamanistic explanation for European Upper Palaeolithic rock art is so interesting - anyone who has visited the cave sites of Spain and France will recognise that one of the most enigmatic aspects of the rock art is why much of

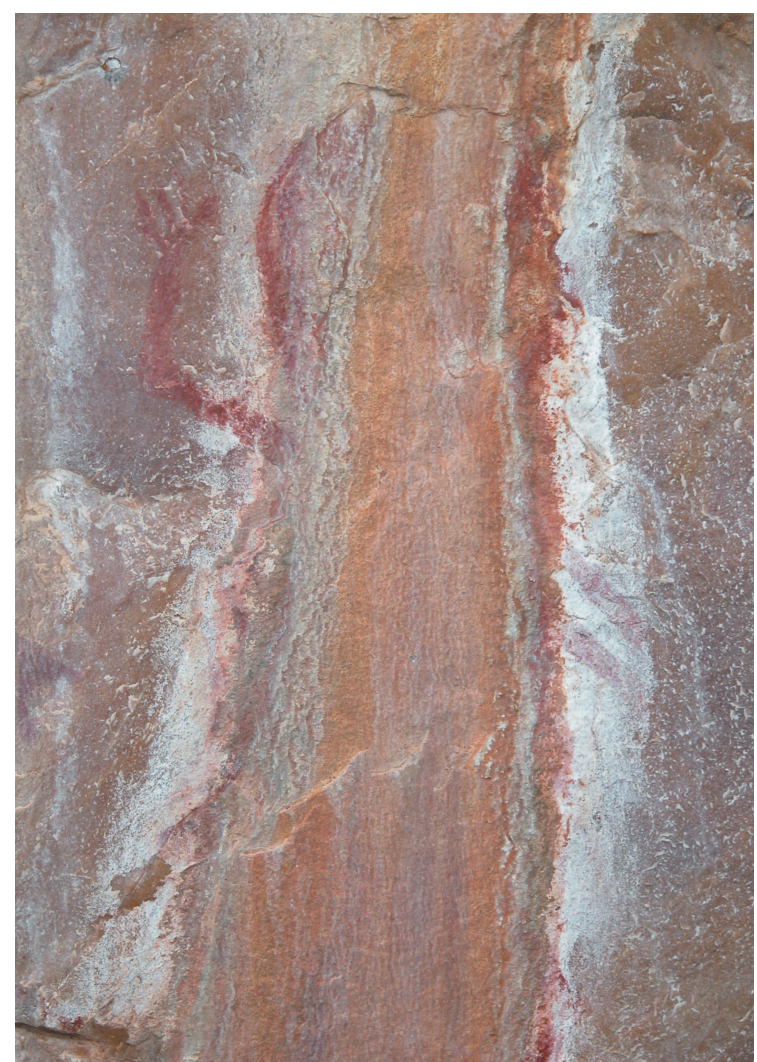

Figure 2 Pictograph of monitor lizard covered over by precipitate wash, from Kurnool District it is placed so deep inside the cave systems, where archaeological evidence indicates no one was living. The shamanistic hypothesis explains this distribution, as well as the interaction between images and rock surface that is often seen in the caves.

I have been asked to discuss the potential application of the shamanistic model to Indian rock art. This is difficult to do. Despite the fact that India possesses one of the richest concentrations of rock art in the world ( see http://www.bradshawfoundation.com/ india/ for an excellent compilation and discussion of the images on the web), the general chronological problems that complicate rock art studies are exacerbated there by a paucity of absolute dates, problematic assertions concerning the relationship between archaeology and rock art, and the fact that rock art seems to have been produced continuously over a very long period (indeed in many places, rock art of one sort or another continues to be created today). The job of identifying clear phases of rock art production (for sites and regions) that must precede more interpretive sorts of analysis is still, in most cases, in its earliest stages. Nonetheless a few comments concerning the possibility of employing the shamanistic model for interpreting Indian rock art are possible.

My first comment concerns the presence of shamanistic practices in India both historically and up to the present day. It is, I think, relevant to ask whether there is within India a shamanistic tradition that could explain some recent rock art, and perhaps have roots that travel deeper back in time. While these questions have not to my knowledge been investigated, the answer to both appears to be yes. Ethnographic and ethnohistorical evidence indicates that there are traditions in India that some refer to as shamanistic, and that involve altered states of consciousness and possession. Indeed, these elements are relatively common in non-Sanskritic Hinduism amongst both caste and tribal populations (eg, Bayly 1994; Gell 1980; Gold 1988; Harper 1957; Rajpramukh 2005). While I have never come across any study of contemporary rock art production in India, I have read discussions of ritual specialists (that we may or may not wish to call shamans) who enter a trance state to interpret rock art (Jain 1984) and who create designs as part of curing ceremonies (Rajpramukh 2005). It seems likely that some of the rock art produced in contemporary India is created by such individuals, and the issue would make a fascinating topic for in depth study. Nonetheless, it is 
also worth warning that Indian shamanism, if indeed it can be labelled as such, is a distinctive entity. The word shamanism may help those not familiar with the region to understand a particular type of religious practice, and it usefully invites inter-regional comparison, but it also masks some crucial unique features of Indian shamanism. A shaman in India, for example, is much less likely to be someone who travels between worlds than someone who acts a vehicle for the divine.

Further back in time the picture naturally becomes much less clear. Nonetheless, one of the best known examples of the use of hallucinogenic drugs for ritual purposes in the past comes from India. The Rg veda, a body of hymns thought to date to perhaps $1500 \mathrm{BC}$, make frequent reference to an intoxicating ritual drink called soma, that was made from a plant and seems to have had psychedelic effects. Turning to prehistoric rock art, there are also some possible indications of shamanistic practices. I have already noted that some south Indian Neolithic rock art from the Deccan plateau may have related to ritual practices involving the percussion of ringing rocks, though whether such practices involved shaman-like individuals, initiates or otherwise is unclear (Boivin 2004). Another rock art tradition with which I am familiar, located in the Kurnool District of Andhra Pradesh, is perhaps a more promising candidate. These still unpublished new sites contain a rich body of paintings that span a time period possibly beginning in the Late Pleistocene and certainly

\section{References}

Bayly, S 1994. Saints' cults and warrior kingdoms in south India. In Thomas, N \& Humphrey, C (eds) Shamanism, History, and the State. Ann Arbor: University of Michigan Press:117-132.

Boivin, N 2004. Rock art and rock music: petroglyphs of the South Indian Neolithic. Antiquity 78 (229):38-53.

Chippindale, C 2003. Trying to test a trance hypothesis in its social context. Cambridge Archaeological Journal 13:218-219.

Gell, A 1980. The gods at play: Vertigo and possession in Muria religion. Man (NS) 15(2): 219-248.

Gold, AG 1988. Spirit possession perceived and performed in rural Rajasthan. Contributions to continuing up to the present day. Amongst the images, which include a diverse array of wild fauna and fish, are found numerous fantastic human forms and hybrid animal-humans (see, for example, figure 1), which could represent shamans or beings encountered by shamans. Much of the rock art is hidden by precipitates and salt washes that have formed as water has flowed across the rock surfaces (figure 2), and some of it may have been deliberately placed in order that it would eventually be covered up - perhaps to return it to a world believed to exist on the other side of the rock face. However, therianthropic images and rock art hidden by precipitates are insufficient in themselves to support a shamanistic interpretation, and the rock art context, at sites littered with microliths, suggests more of an everyday context than any kind of special ritual setting.

Overall, I would argue that while there are suggestive indications that shamanistic practices may be behind some of India's rich corpus of rock art, there is not yet, as far as I am aware, any particularly strong case to be made for the shamanistic production of rock art in the region. The shamanistic interpretation does, however, offer a potentially fruitful line of enquiry, particularly for more recent art, much of which was probably created in the context of a society where ritual practice frequently involved altered states of awareness.

Indian Sociology (ns) 22(1):35-63.

Harper, EB 1957. Shamanism in south India. Southwestern Journal of Anthropology. 13:267287.

Jain, J 1984. Painted Myths of Creation: Art and Ritual of an Indian Tribe. New Delhi: Lalit Kala Akademi.

Rajpramukh, KE 2005. The shaman in Asia-pacific region: A cross-cultural study. Man in India 85(1\&2):25-40.

\section{Website}

http://www.bradshawfoundation.com/india/ 